\title{
The Research on Shear Properties of Deformable Ground Soil under High-speed Driving Conditions
}

\author{
LYU Wei-wei ${ }^{1, a}$, LI Zhong-xin and LOU Peng \\ ${ }^{1}$ School of Mechanical Engineering, Beijing Institute of Technology, Beijing 100081, China
}

\begin{abstract}
The classical ground soil shear mechanics model is difficult to predict the maneuverability of vehicles under high-speed driving conditions. The shear mechanical properties of soil under dynamic loading are the key factor to research on the ground attachment characteristics of vehicles under high-speed driving conditions. The relationship between the shear properties of the ground soil and the loading rate was analyzed by numerical simulation method. Based on the Janosi shear model of the ground soil, the loading rate and shear rate were supplemented to establish the applicable driving conditions for high-speed and heavy-duty vehicles. The ground soil shearing characteristics model provides a theoretical basis for researching on the vehicle's driving maneuverability under high-speed driving conditions.
\end{abstract}

\section{Janosi shear model for classic ground soil}

There are two kinds of shear stress-deformation characteristic curves for common ground soil at low shear rate. As shown in Fig. 1, the abscissa is the shear displacement and the ordinate is the soil shear stress. One is to describe the brittle ground soil, such as compacted sand, frozen snow, and other undisturbed hard ground. The shear stress-strain curve of this kind of soil will have a maximum value, and the shear stress of the soil will be smooth after reaching the yield limit. The shear models describing the brittle soil are: Bekker shear model, JYWong shear model and so on. The other is plastic soil, such as loose sand, dry soil, and other disturbed ground soil, the shear stress-strain curve of this kind of soil has no peak of protrusion, and it always changes smoothly. The shear models describing plastic soils are: Janosi shear model, hyperbolic shear model, pure exponential shear model, etc.[1-5].

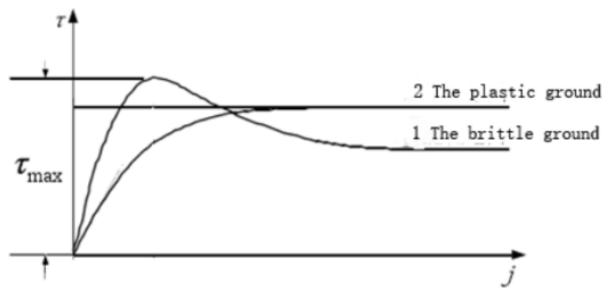

Figure 1. Two common soil shear

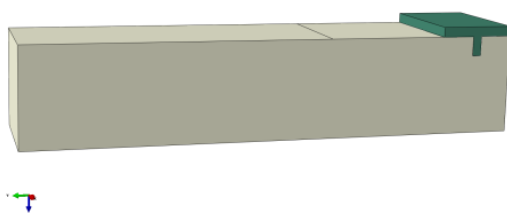

Figure 2. Simulation model of sheared stress-strain curves soil test for track shoes

${ }^{a}$ Corresponding author : lvweiwei@bit.edu.cn 
For the plastic shear properties of deformable ground soil, there is no hump in the shear stress-strain curve, so the Janosi shear model is adopted[3]to describe the shear properties of ground soil at low shear rates, as follows:

$$
\begin{gathered}
\tau=\tau_{\max }^{0}\left(1-e^{-\frac{j}{k_{m}}}\right) \\
\tau_{\max }^{0}=c+p \tan \varphi
\end{gathered}
$$

Where, $j$ is shear displacement; $k_{m}$ is shear modulus; $\tau_{\max }^{0}$ is soil shear strength at low shear rates; $\tau$ is shear stress; $c$ is soil cohesion; $\varphi$ is the internal friction angle of the soil; $p$ is soil normal pressure.

\section{Analysis of soil shear characteristics}

\subsection{Soil shear characteristics simulation model}

(1)Numerical calculation model.Simulation model of the shear plate shear test in Fig. 2. Due to the limitation of indoor soil trough size, in order to reduce the influence of the shearing force of the side of the track shoe and the soil on the soil shear characteristics, the shortest side of the soil model is consistent with the short side width of the track plate. The structural parameters of the track shoes are $200 \mathrm{~mm} \times 150 \mathrm{~mm} \times 15 \mathrm{~mm}$, and the structural parameters of the spurs are $150 \mathrm{~mm} \times 10 \mathrm{~mm} \times 8 \mathrm{~mm}$. When researching on the shearing soil test of track shoes under high shear rate conditions, the calculated soil sizes for the track shoes and the ground are: $495 \mathrm{~mm} \times 165 \mathrm{~mm} \times 60 \mathrm{~mm}$ and $165 \mathrm{~mm} \times$ $1000 \mathrm{~mm} \times 200 \mathrm{~mm}[2-7]$.

(2)Selection of model materials and unit types. The ABAQUS finite element software was used to establish the crawler plate and deformable ground soil simulation model. The track shoes, pressure plate and deformable ground unit model were selected as C3D4 solid elements. The material of track shoes and pressure plate was defined as rigid body, and the soil material was selected as elastoplastic Drucker-Prager constitutive material. The parameters defined for the track shoes, the press plates and the Kangzhuang soil material model with a moisture content of 5\% are shown in Tables 1 and 2 [6-7].

Table 1 Material model parameters of track shoes and pressure plates

\begin{tabular}{|c|c|c|}
\hline Density $\rho / \mathrm{g} \cdot \mathrm{mm}^{-3}$ & Elastic Modulus $E / \mathrm{kPa}$ & Poisson ratio $\mu$ \\
\hline $7.85 \times 10^{-3}$ & $2.05 \times 10^{6}$ & 0.3 \\
\hline
\end{tabular}

Table 2 Soil Drucker-Prage elastoplastic constitutive model parameters

\begin{tabular}{|c|c|c|c|c|c|c|c|c|}
\hline $\begin{array}{c}\text { Confining } \\
\text { pressure } \\
\sigma_{3} \mathrm{kpa}\end{array}$ & $\begin{array}{c}\text { density } \\
/ \mathrm{g} \cdot \mathrm{mm}^{-3}\end{array}$ & $\begin{array}{c}\text { Elastic } \\
\text { Modulus } E \\
\text { kpa }\end{array}$ & $\begin{array}{c}\text { Internal } \\
\text { friction } \\
\text { angle } \beta \\
/ \text { rad }\end{array}$ & $k_{1}$ & $\begin{array}{c}\text { Dilatancy } \\
\text { angle } \\
/ \text { rad }\end{array}$ & $\begin{array}{c}\text { Yield } \\
\text { stress } \\
\sigma_{c / \mathrm{kpa}}^{0}\end{array}$ & $\begin{array}{c}\text { Plastic } \\
\text { strain } \\
-p l\end{array}$ & $\begin{array}{c}\text { Poisson } \\
\text { ratio } \\
\mu\end{array}$ \\
\hline 100 & $1.82 \times 10^{-3}$ & 396 & 0.99 & 0.778 & 0 & 49 & 0 & 0.3 \\
\hline
\end{tabular}




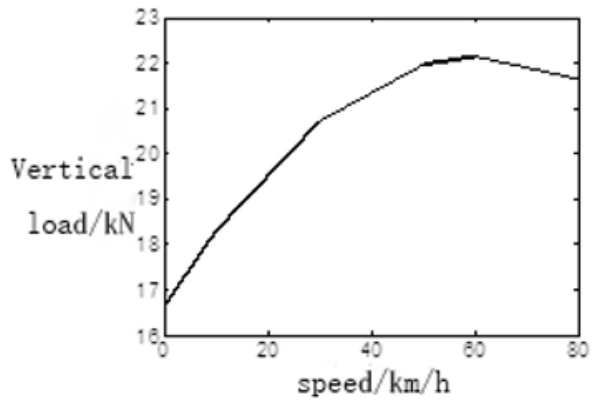

Figure 3 Relationship between driving speed and vertical load of vehicle to ground

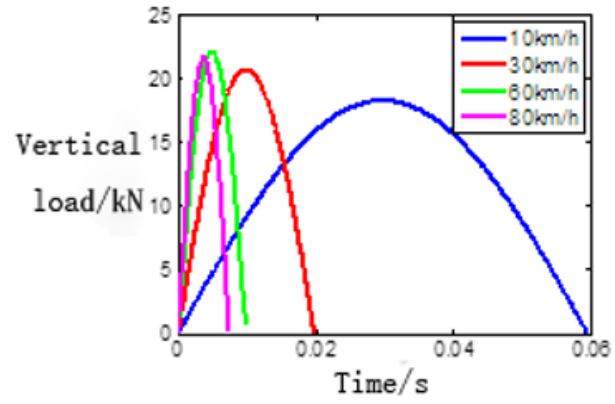

Figure 4 Semi-sinusoidal loading curve at four vehicle speeds

(3) Boundary conditions. The pressure characteristics of the deformable ground soil are studied, and the degrees of freedom in the three directions of the bottom surface of the ground soil model in Fig. 2 are all constrained, and the load or displacement in the direction of the vertical contact surface is applied to the pressure plate in Fig. 3 and Fig. 4, and all the degrees of freedom of the pressure plate except the $\mathrm{Z}$ direction are constrained.

\subsection{Influence of shear rate and water content on soil shear strength}

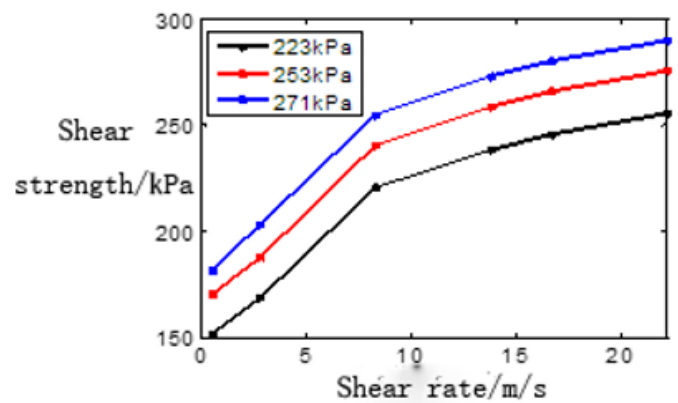

Figure 5 Relationship between soil shear strength and different normal pressures

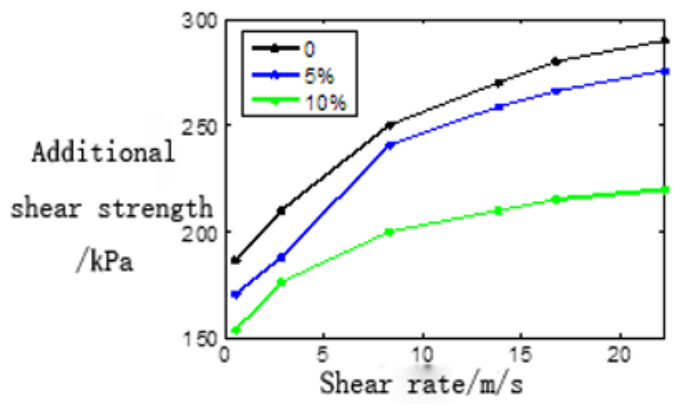

Figure 6 Relationship between shear rate and shear rate of soil with different water content

Figure 5 shows the relationship between soil shear strength and shear rate under different normal pressures. The vehicle's driving speed is $10 \mathrm{~km} / \mathrm{h}, 30 \mathrm{~km} / \mathrm{h}, 60 \mathrm{~km} / \mathrm{h}$. The normal compressive stress of the track plate on the deformable ground soil is $223 \mathrm{kPa}, 253 \mathrm{kPa}, 271 \mathrm{kPa}$, the soil shear strength begins to change with the shear rate, and then tends to a fixed value. As shown in Fig. 5, the normal pressure of the track shoes is $223 \mathrm{kPa}$, the horizontal displacement is $150 \mathrm{~mm}$, and the moving speeds are $0.2 \mathrm{~m} / \mathrm{s}, 0.5 \mathrm{~m} / \mathrm{s}, 2.78 \mathrm{~m} / \mathrm{s}, 8.3 \mathrm{~m} / \mathrm{s}, 13.8 \mathrm{~m} / \mathrm{s}, 16.7 \mathrm{~m} / \mathrm{s}$ and $22.2 \mathrm{~m} / \mathrm{s}$. Relationship between soil shear strength and shear rate with water content of $0,5 \%$ and $10 \%$ respectively. The three curves show the variation of soil shear strength and shear rate of three different water contents. The soil with higher water content increases with the increase of shear rate, and it is easier to reach a stable state. The green curve in Figure 6 indicates the water content of $10 \%$ soil, as the shear rate increases, its shear strength changes quickly to level and increases no longer[8-11].

\subsection{Shear rate amplification factor}

The variation law of shear rate of ground soil under high-speed conditions was studied. A parameter reflecting the influence of shear rate on shear strength was proposed, that is shear magnification factor 
$\eta \cdot \eta$ is the ratio of shear strength at different shear rates to soil shear strength at low shear rates, with magnification factor $\eta$ is for the ordinate, the shear rate is for the abscissa.

Therefore, the relationship between the amplification factor and the shear rate can be expressed as:

$$
\begin{aligned}
& \frac{v_{2}}{\eta}=a_{2}+b_{2} v_{2} \\
& \eta=\frac{\tau_{\max }}{\tau_{\max }^{0}}
\end{aligned}
$$

where, $v_{2}$ is the rate of movement of the track shoe relative to the ground, ie the shear rate; $\eta$ is magnification factor, dimensionless; $a_{2}$ and $b_{2}$ are the intercept and slope of the extension line and the ordinate axis of the fitted straight line,respectively; $\tau_{\max }^{0}$ is soil shear strength at low shear rates; $\tau_{\max }$ is soil shear strength at high shear rates.

(1) The variation of shear strength and shear rate under different normal pressures. It can be seen from Fig. 7 that the soil shear strength amplification factor and the shear rate change trend are similarunder different normal pressures. The larger the normal pressure, the soil is compacted, the internal pores are further reduced, and the soil shear amplification factor changes. The smaller the difference, the lower the normal pressure amplification factor and the shear rate change are rather the higher the normal pressure.

The shear rate is always greater than 0 , the ratio of the shear rate to the magnification factor is the ordinate, the shear rate is the abscissa, and the magnification coefficient and the shear rate curve are transformed into coordinates to obtain three nearly coincident lines (as shown in Figure 7). When the shear rate is $0.5 \mathrm{~m} / \mathrm{s}$, the soil shear strength amplification coefficient is 1under different normal pressures, and 3 straight lines intersect with one point. Different normal pressures influence the intercept on the straight line and the ordinate axis $a_{2}$, and the slope of the line $b_{2}$. The greater the normal pressure, the slope of the line $b_{2}$ is larger, the intercept on the line and the ordinate axis $a_{2}$ is smaller.

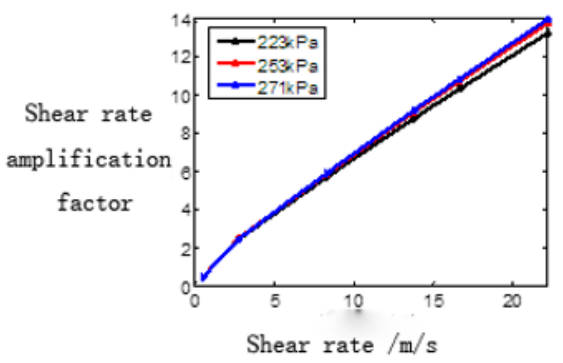

Figure 7 Relationship between different normalpressure andshear rateamplification factor

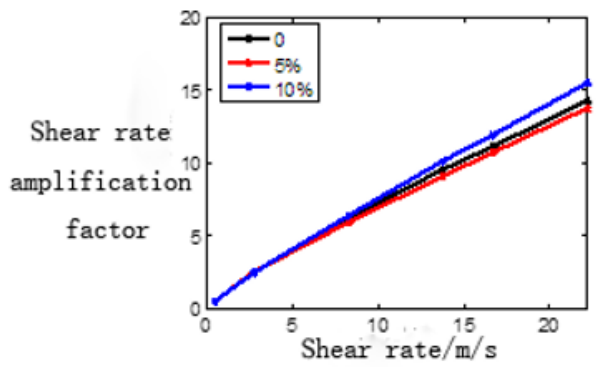

Figure 8 Relationship between different water and shear rateamplification factor

(2) Effect of differentmoisture content on soil shear strength

The three straight lines indicate the relationship between the shear rate and the amplification factor ratio of the three water contents soils and the shear ratein Fig. 8. The higher the water content, the larger the slope of the line. The three straight lines intersect with one point, which indicates the soil shear strength at a low shear rate of $0.2 \mathrm{~m} / \mathrm{s}$, where the soil strength amplification factor is 1 , so that the three straight lines intersect at the same point in the coordinate system. Different water content and different normal pressureinfluence on the intercept and straight line slope of the linear extension line and the ordinate, indicating t the relationship between shear rate and soil shear strength under different normal pressures and soil moisture content can be described by parameters $a_{2}$ and $b_{2}$. 


\subsection{Influence of soil water content and normal pressure on model parameters $a_{2}$ and $b_{2}$}

The research found that the soil strength amplification factor is directly related to soil water content and normal pressure. The parameters obtained by analyzing the three water contents, three normal pressure shear rates and the shear rate curve are shown in Fig. 9 and Fig. 10 The relationship between rate and normal pressure and parameter sum.

Soil strength factorIt is directly related to soil water content and normal pressure. The parameters obtained by analyzing three kinds of water content, three kinds of normal pressure shear rate and shear rate curve are analyzed. $a_{2}$ with $b_{2}$ Figure 9 and Figure 10 show soil moisture content and normal pressure and parameters. $a_{2}$ with $b_{2}$ Relationship.

The red dots indicate the parameters $a_{2}$ and $b_{2}$ obtained for different moisture content and normal pressure in Figures 9 and 10. The moisture content has a great influence on the parameter $a_{2}$ and $b_{2}$ The moisture content increase, parameter $a_{2}$ decreases rapidly and the parameters $b_{2}$ gradually increase; the normal pressure has little effect on the parameters $a_{2}$. In Fig. 9, the normal pressure increases and the parameters has not changed much at the same moisture content. In Figure 10, when the normal pressure increases, the parameters $b_{2}$ show a trend of increasing first and then decreasingat the same moisture content.

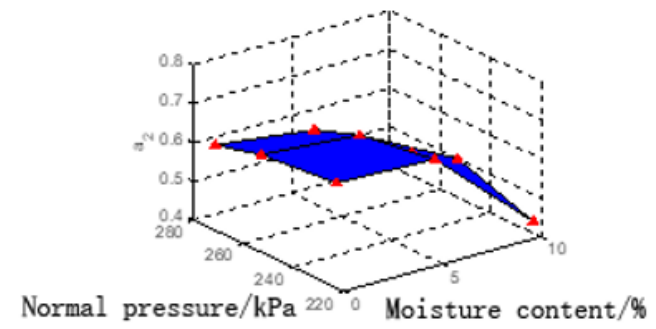

Figure 9 Influence of moisture content and normal pressure on parameters $a_{2}$

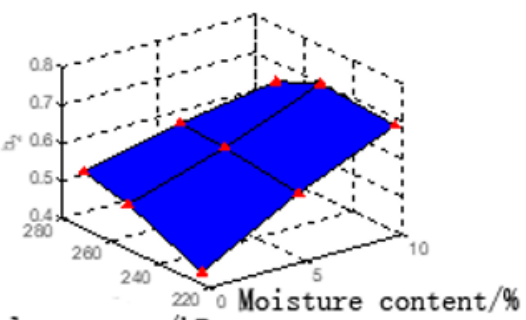

Normal pressure $/ \mathrm{kPa}$

Figure 10 Influence of moisture content and normal pressure on parameters $b_{2}$

\section{3 shear correction model}

The shear deformation of deformable ground soil is affected by the shear rate of the track shoes and the vehicle's load on the ground. Under the same load, the shear rate can increase the strength of the soil. Based on the Coulomb model [12-15], shear is introduced. Intensity amplification factor, establish a soil strength formula related to driving speed.

$$
\tau=\tau_{\max }\left(1-e^{-\frac{j}{k_{m}}}\right)=\eta \tau_{\max }^{0}\left(1-e^{-\frac{j}{k_{m}}}\right)=\frac{v_{2}}{a_{2}+b_{2} v_{2}}(c+p \tan \varphi)\left(1-e^{-\frac{j}{k_{m}}}\right)
$$

Where, jis shear displacement; kmisshear modulus; $\tau_{\max }^{0}$ is soil shear strength at low shear rates; $\tau$ is shear stress; $c$ is soil cohesion; $\varphi$ is the internal friction angle of the soil; $p$ is soil normal pressure; $\mathrm{v} 2$ is the rate of movement of the track shoe relative to the ground, is the shear rate $(v \geq 0.2 \mathrm{~m} / \mathrm{s}) ; \eta$ is soil strength amplification factor, dimensionless; $a_{2}$ and $b_{2}$ are the intercept and slope of the extension line and the ordinate axis of the fitted straight line, respectively; $\tau_{\max }$ is soil shear strength at high shear rates. 
Table 3 Model parameters before and after soil shear model correction

\begin{tabular}{|c|c|c|}
\hline Model parameter & Before correction & After correction \\
\hline Moisture content $w / \%$ & 4 & 4 \\
\hline Cohesion $c / \mathrm{kPa}$ & 17.82 & 33.7 \\
\hline Internal friction angle $\varphi / \%$ & 33.7 & 10 \\
\hline Shear rate $v_{2} / \mathrm{m} / \mathrm{s}$ & 10 & 223 \\
\hline Normal pressure $p / \mathrm{kPa}$ & 223 & 10 \\
\hline Shear deformation modulus $k_{m} / \mathrm{mm}$ & 12 & 0.66 \\
\hline$a_{2} / \mathrm{m} / \mathrm{s}$ & 0 & 0.5 \\
\hline$b_{2}$ & 0 & \multirow{2}{*}{0.5} \\
\hline
\end{tabular}

Using the parameters in Table 3, using the modified shear model for calculation, comparing the calculation results before the correction with the numerical simulation results, which shows that the corrected model has a better prediction effect, and the error with the numerical calculation result is up to $25 \%$.

\section{References}

1. Wong J. Y., Huang W. "Wheels vs. tracks"A fundamental evaluation from the traction perspective[J]. Journal of Terramechanics, 2006, 43(1): 27-42.

2. Zhuang Jide, Calculating Vehicle Ground Mechanics [M]: Mechanical Industry Press, 2002.

3. Zhang Keyuan, Vehicle Ground Mechanics [M]: Beijing: National Defense Industry Press, 2002.

4. Park W. Y., Chang Y. C., Lee S. S.et al. Prediction of the tractive performance of a flexible tracked vehicle[J]. Journal of Terramechanics, 2008, 45(1): 13-23.

5. Liu K., Ayers P., Howard H.et al. Influence of soil and vehicle parameters on soil rut formation[J]. Journal of Terramechanics, 2010, 47(3): 143-150.

6. Al-Milli S., Seneviratne L. D., Althoefer K. Track--terrain modelling and traversability prediction fortracked vehicles on soft terrain[J]. Journal of Terramechanics, 2010, 47(3): 151-160.

7. Lyasko M. LSA model for sinkage predictions[J]. Journal of Terramechanics, 2010, 47(1): 1-19.

8. Lyasko M. Slip sinkage effect in soil--vehicle mechanics[J]. Journal of Terramechanics, 2010, 47(1): 21-31.

9. Lyasko M. Multi-pass effect on off-road vehicle tractive performance[J]. Journal of Terramechanics, 2010, 47(5): 275-294.

10. Lyasko M. I. How to calculate the effect of soil conditions on tractive performance[J]. Journal of Terramechanics, 2010, 47(6): 423-445.

11. Alaoui A., Diserens E. Changes in soil structure following passage of a tracked heavy machine[J]. Geoderma, 2011, 163(3): 283-290.

12. Abo-Elnor M., Hamilton R., Boyle J. T. 3D Dynamic analysis of soil--tool interaction using the finite element method[J]. Journal of terramechanics, 2003, 40(1): 51-62.

13. Lee J. H. Finite element modeling of interfacial forces and contact stresses of pneumatic tire on fresh snow for combined longitudinal and lateral slips[J]. Journal of Terramechanics, 2011, 48(3): 171-197.

14. Hambleton J. P., Drescher A. Modeling wheel-induced rutting in soils: Rolling[J]. Journal of Terramechanics, 2009, 46(2): 35-47.

15. Hambleton J. P., Drescher A. Modeling wheel-induced rutting in soils: indentation[J]. Journal of Terramechanics, 2008, 45(6): 201-211. 